\title{
Convalescent Plasma Therapy in Effort of Weaning from Mechanical Ventilation Using Music Stimulation in Severe COVID-19 Patients
}

\author{
Made Ayu Dessy Dwitasari ${ }^{1}$, Anak Agung Ayu Putri Laksmidewi ${ }^{2 *}$ \\ ${ }^{1}$ Department of Resident of Neurology, Medical Faculty, Udayana University, Sanglah General Hospital, Indonesia; ${ }^{2}$ Department \\ of Neurology, Medical Faculty, Udayana University, Sanglah General Hospital, Indonesia
}

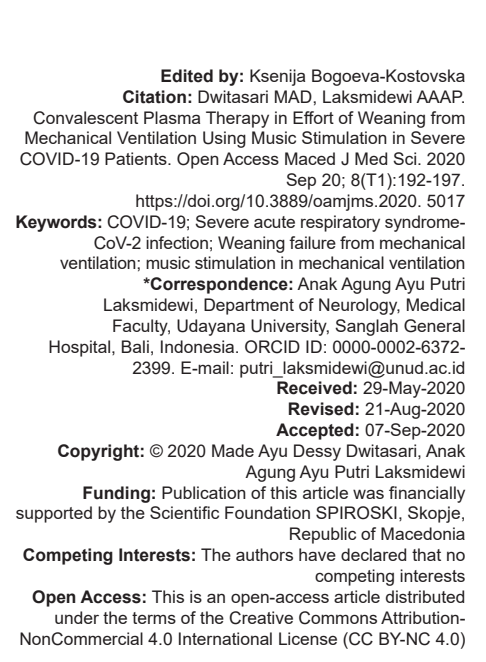

Abstract

Nowadays, severe acute respiratory syndrome coronavirus-2 (SARS-CoV-2) or CoV disease of 2019 (COVID-19) infection is a big threat to global health and becomes a global pandemic. The exact treatment for this disease is still an on-going experiment. Meanwhile, there are more people infected by this disease, leading to severe acute respiratory syndrome (SARS). COVID-19 patients with severe clinical symptoms may need mechanical ventilation. These patients at the same time, struggle with the infection and also the effort to wean from the ventilation. Weaning failure commonly occurred in patients with severe respiratory disease. In this article, we discuss the use of convalescence plasma therapy and the benefit of music stimulation for weaning from mechanical ventilation in COVID-19 patients.

\section{Introduction}

Since December 2019, the epidemic of SARSCoV-2 has rapidly spread worldwide. Originating in Wuhan, China, this disease has affected hundreds of nations within 4 months. The outbreak of SARS-CoV-2 has become a major concern all over the world [1]. Pneumonia that induced by the SARS-CoV-2 is named CoV disease 2019 (COVID-19). As it has affected thousands of people, the World Health Organization has declared that this disease is a pandemic [2].

Lack of study and knowledge about further treatment has led to many deaths due to the severity of the symptom and comorbid. The efficacy of recent treatment is still on clinical evaluation and investigation, due to there are no approved specific antiviral agents, it is an urgent need to look for an alternative treatment strategy for COVID-19. In order to prevent death among the severe COVID-19 patients [3].

Severe pneumonia caused by human CoV was characterized by rapid viral replication, massive inflammatory cell infiltration, and elevated pro-inflammatory cytokines or even cytokine storm in alveoli of lungs, resulting in acute pulmonary injury and acute respiratory distress syndrome (ARDS). COVID-19 is a type III hypersensitivity reaction due to antigen-antibody immune complex deposition with complement activation [4], [5]. Recent studies on COVID-19 demonstrated that the lymphocyte counts in the peripheral blood were remarkably decreased and the levels of cytokines in the plasma from patients requiring intensive care unit (ICU) support, including interleukin (IL)6, IL-10, tumor necrosis factor (TNF)- $\alpha$, and granulocytemacrophage colony-stimulating factor, were significantly higher than those who did not require ICU conditions [6], [7].

Recently, a Group of study regarding the use of convalescent plasma (CP) therapy as one of COVID19 treatment. Are still on going research and need to be tested tin severe COVID-19 patients. As we know, $\mathrm{CP}$ therapy is classic adaptive immunotherapy and has been applied as a treatment of many infectious diseases. This therapy has been acknowledged more than one century. In 2003, this therapy had been used as a treatment in SARS patients $(n=80)$ at Prince Wales Hospital, Hong Kong. It had been reported that this therapy demonstrated clinical deterioration despite treatment with methylprednisolone and most of the patients demonstrated good clinical outcome, 
associated with there was no adverse effect reported during the plasma infusion [8], [9], [10].

In association of the clinical symptom severity and comorbid disease, there were many patients experience the need of mechanical ventilation. As many of the patients experience mechanical ventilation, most of patient having a difficulty in the effort of weaning from mechanical ventilation. This condition was believed related to the dysfunction of the brain during the ventilation. There is a complex interaction between lung and brain in critically ill patients who experienced mechanical ventilation. This review will discuss the effect of music stimulation in weaning from mechanical ventilation among COVID-19 patients.

\section{CP Therapy for COVID 19}

As we know, until now, there are still no approved specific antiviral agents for novel CoV disease. Many clinicians and scientists are trying to find an alternative treatment for severe COVID-19 patients, considering the mortality rate still increasing. CP or immunoglobulin is the last resort to improve clinical outcome and survival rate of patients SARS-CoV-2. This therapy known as classic adaptive immunotherapy and had been known for many infectious diseases more than one century. Driven by passive immunity driven bay $\mathrm{CP}$ can provide neutralizing antibodies (NAbs) that restrain the infection [11]. SARS-CoV 2 infection induces IgG antibodies production against nucleoprotein that can be detected at day 4 after the onset of disease and with seroconversion at day 14 . Shen et al. showed that recovered donors from COVID-19 infection had specific antibody titers ranging between 1.800 and 16.200 and NAbs titers were between 80 and 480 . The plasma obtained from the donors and transfused in the recipients on the same day leads to viral load decreased. The presence of NAbs in the recipients played a key role in the restriction of viral infections. This study showed that the titers of NAbs in patients infected with SARS-CoV-2 were low before day 10 post-disease onset and then increased, with a peak 10-15 days after disease onset, remaining stable thereafter in all patients [12], [13].

This treatment had been recommended by $\mathrm{WHO}$ as an empirical treatment during the outbreak of Ebola virus in 2014. Moreover, it was also successfully used in the treatment of SARS, Middle East respiratory syndrome (MERS), and H1N1 pandemic in 2009 with good and satisfactory clinical outcomes and safety. This treatment associated with the condition of most patients of SARS-CoV-2 whose continue to deteriorate despite treatment with a corticosteroid. Although, according to WHO, the management of COVID-19 mainly focused on infection prevention, case detection and monitoring, and supportive care. Until now, May 2020, no specific treatment is recommended due to the lack of study and clinical evidence [14].

CP therapy was obtained from recovered patients who had established humoral immunity against the virus, contains a large quantity of NAbs of the virus, and eradicates the pathogen from blood circulation and pulmonary tissues. However, the CP therapy was unable to improve the survival in Ebola virus disease due to the absence of data of NAb titration for stratified analysis. Since the virological and clinical characteristics among MERS and SARS were similar to COVID-19, it is suggested that $\mathrm{CP}$ therapy might be an option for alternative treatment for COVID-19 patients. Patients who have recovered from COVID-19 with a high NAb titer may be a valuable donor source of CP [15].

This CP therapy had been applied for COVID-19 patients in China on January 2020, with 10 participants of severe COVID-19 patients. This trial using one dose of $200 \mathrm{ml} \mathrm{CP}$ transfusion was well tolerated. Among those patients, there are three patients received mechanical ventilation and the others received high flow and low-flow nasal cannula oxygenation. From this trial, after treatment with $\mathrm{CP}$, two patients were weaned from mechanical ventilation to high-flow nasal cannula. Moreover, the clinical symptoms significantly improved within 3 days, followed by the rapid neutralization of viremia [16].

A case series by Shen et al., from January 2020 to March 2020, evaluates the benefit of CP therapy in five critically ill patients with laboratory-confirmed COVID-19 and ARDS with severe pneumonia and mechanical ventilation. All five were treated with $\mathrm{CP}$. This study suggested that viral load declined within days of treatment, and the clinical symptoms were improved. Among those patients, four of them who had been receiving mechanical ventilation and ECMO no longer required respiratory support after plasma transfusion [17].

\section{Effort of Weaning from Mechanical Ventilation in COVID-19 Patients}

In severe COVID-19 patients, most of the cases required critical care management, including mechanical ventilation. Mechanical ventilation is the most common life-sustaining therapy for COVID-19 patients in ICU. It temporarily replaces spontaneous breathing in COVID-19 patients who suffered from respiratory failure [18].

Many patients who receive ventilator support are "fighting their ventilator" at some point of their therapy. This condition, referred to as "patient-ventilator asynchrony," described the fact that a mechanically ventilated patient keeps a spontaneous respiratory activity and this activity is not in phase with the machine. 
This usually happened during awakening from sedation or during ventilator weaning [19].

Weaning defined as the withdrawal of mechanical ventilation to re-establish spontaneous breathing. Weaning covers the entire process of liberating the patient from mechanical support and from the endotracheal tube. Weaning comprises $40-50 \%$ of the total duration of mechanical ventilation. Approximately $70 \%$ of patients in intensive care successfully weaned without difficulty on the first attempt. While other patients experience more difficulty or prolonged period of weaning, this may lead to a poorer prognosis. Some issue was considered as the caused, but the most possible cause is the weakness or fatigue of the diaphragm and the accessory muscle of inspiration that leads to the failure of weaning from mechanical ventilation. Another cause is considered that mechanical ventilation affects the diaphragmatic structure and functions, known as ventilator-induced diaphragmatic dysfunction, related to the changes in myofiber length and rapid atrophy [20].

Long duration of bed rest and immobility in critical ill patients may result in profound physical deconditioning. These effects may be induced by inflammation, lack of glycemic control, and pharmacological agents. The incidence of skeletal muscle weakness in the ICU is observed in $25 \%$ of ventilated patients. Inspiratory muscle training is a technique that loads the diaphragm and accessory inspiratory muscle to improve strength and endurance [20].

During the pandemic of COVID-19, due to the severity of clinical symptoms can lead to respiratory failure, many patients required mechanical ventilation. Weaning from mechanical ventilation is very essential in the care of critically ill intubated patients, especially those who suffered from SARS-CoV-2. This process related to the entire process of liberating the patient from mechanical support and from the endotracheal tube, needs the involvement of the good function of the brain as well. Critically ill patients develop neuropsychological disturbance. Neurocognitive sequelae frequently occurred among critically ill patients [20].

\section{Lung-brain Interactions in Mechanically Ventilated COVID-19 Patients}

COVID-19 patients with severe clinical symptoms are associated with high morbidity and mortality rate. Those patients may require mechanical ventilation. Some of them survive the condition while others may not survive from this pandemic. Those patients who survive and still receive mechanical ventilation may suffer neuropsychological alterations such as memory impairment. Although mechanical ventilation is important life support for many critical patients, especially in COVID19 patients with a severe symptom, it is not without complication. It is intrinsically able to be worsening with possible spread to other organs, including the brain, and ultimately leading to multiorgan failure [21]

Studies described regarding mechanism implicated in lung-brain interaction during mechanical ventilation have been less investigated. It suggested that cognitive impairment seen in patients who received mechanical ventilation [22]. The etiology of these neurocognitive deficits is probably a multifactorial cause such as hypoxemia, the use of sedative and/or analgesics, hypotension, altered regulation of blood glucose levels, the duration of mechanical ventilation usage, the length of stay in the ICU, and the presence of confusional syndrome [23]. Many clinical studies had shown that mechanical ventilation may induce a biological response through infiltration of monocytes and macrophages, the release of mediator inflammation. This mechanism may lead to lung damage. Some studies also suggested that there is a relationship between hypoxia and hippocampal damage since hippocampus is the brain structure related to learning and memory capacity, it is also known to be vulnerable to hypoxia. There is also evidence that ARDS can induce structural alterations in the hippocampus. These studies support the existence of a brain-lung communication axis associated with the release of catecholamines, neurokinins, and neuropeptides [24].

During mechanical ventilation, the lung generates information through the stimulation of the mechanoreceptors or chemoreceptors, which reaches the central nervous system (CNS) through other routes. By this mechanism, the brain responds by altering the

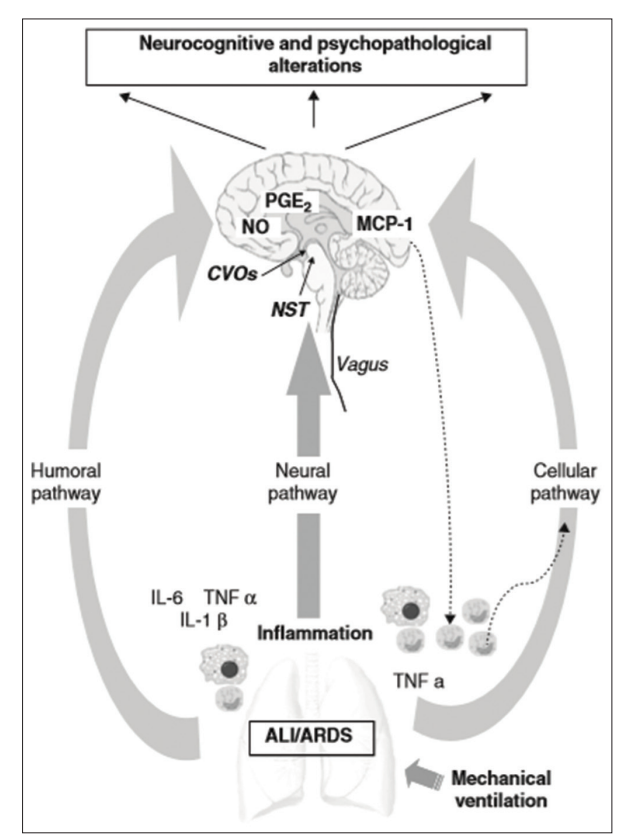

Figure 1. Interaction pathway between the lungs and central nervous system (CNS) during mechanical ventilation. The CNS receives information from the peripheral through three pathways: Humoral, neural, and cellular pathway [26], [27] 
permeability of the blood-brain-barrier or by modifying cerebral blood flow. Communication pathways between peripheral and CNS are illustrated in Figure 1. First pathway is the humoral pathway, through inflammatory mediators such as IL-6, TNF- $\alpha$, and IL-1 $\beta$, by the recruitment of peripheral monocytes or macrophages, may directly reach the brain [25].

COVID-19 infection, particularly, has a very close relation to respiratory distress since many of the patients suffer from respiratory failure and require mechanical ventilation. In COVID-19, patients who received mechanical ventilation considered to have a similar mechanism between lung and brain communication pathway during mechanical ventilation. An inadequate ventilation strategy may induce the release of certain inflammatory mediators or metabolites into the bloodstream, which can be detected by the CNS. An experimental study by Quilez et al. evaluated neuronal activation in a model of mechanical ventilation damage in rats. The lungs and brain share the same inflammatory mediators, and once these are released into the bloodstream, they can also make contact with the brain by interacting with specific CNS receptors. This mechanism involves an active transport mechanism which leads to the release of prostaglandin E2 and nitric oxide [24].

\section{Possibility of Weaning Failure in COVID- 19 Patients}

Weaning is an essential process, especially in severe COVID-19 patients who receive mechanical ventilation and involve a series of stages in the process of care. The weaning process involves a gradual decrease in ventilator settings as a patient's respiratory status improves, leading to termination of mechanical ventilation support. For some patients, weaning may be difficult due to the patients cannot tolerate independent respirations when the artificial airway is removed [25]. Extubation failure is the inability to sustain spontaneous breathing after removal of the artificial airway with the need for re-intubation within 24-72 $\mathrm{h}$. The incidence rate of extubation failure is reported to be $26-42 \%$. This failure associated with a high mortality rate. From a study by Coplin et al., the mortality rate was $12 \%$ if there was no delay in extubation and $27 \%$ when extubation was delayed [28].

\section{Music Stimulation during Mechanical Ventilation and Weaning in COVID-19 Patients}

To do a lifesaving intervention, one of the management is the initiation of mechanical ventilation to treat acute respiratory failure. This involved the administration of numerous sedative and analgesic medication which can prolong ventilation and increase the length of ICU stay [29]. As the patients recover from acute respiratory failure, they can be weaned from ventilator support. There are many factors associated with the success of weaning, such as respiratory muscle strength, adequate respiratory drive, acidbase balance, neurological status, and psychological readiness [20]. Extubation failure can lead to ventilatorassociated pneumonia, airway trauma, increased costs, and higher mortality rates [30].

Some studies suggested than a number of non-pharmacological interventions have been shown to be an advantage for anxiety symptoms in ICU patients, this intervention such as music intervention. As we know, in ventilated patients, some of the patients may suffer anxiety during mechanical ventilation. Decreasing anxiety believed to be helpful in promoting ventilator weaning, especially in COVID-19 patients. Music is a non-pharmacological intervention that integrates physiological and psychological components to reduce stress and anxiety and ultimately promotes overall conditions [31], [32], [33].

A study held by Hunter et al. and Lee et al. had demonstrated that music is an effective complement in a certain condition of weaning difficulty by decreasing anxiety. The duration, frequency, and timing of music intervention approximately at least 30 min music-listening session once per day, from 1 day to up to 30 days. The following music programs were used as a preference: Western classical music, Chinese classical music (e.g., bamboo flute, rain, and tears), and music of natural sounds. All of the music had slow beat (60-80 beats/min) that corresponds to a normal heart rate and thought to be relaxing for the patients [32], [33], [34].

\section{Conclusion}

Based on our findings in this article, in severe and critically ill of COVID-19 patients, most patients urgently required mechanical ventilation. One of the problems regarding this management is the weaning failure from mechanical ventilation. Recently, many studies develop other treatment strategies for COVID19 patients. One of the effective treatments is CP therapy. In order to decrease the weaning failure rate in critically ill of COVID-19 patients, the author suggests the use of CP therapy priory the weaning process.

Regarding the possibility of weaning failure, we suggest to give music stimulation to decrease the psychological symptoms for patients undergoing mechanical ventilation. There are studies suggested that music intervention may lead to improve patients conditions and help to reduce patients' anxiety levels. 
These anxiety levels can be measured by indicators of blood pressure, heart rate, and respiration rate. Some study also measures the serum cortisol levels and stated that patients that received music intervention had lower serum cortisol levels. We hypothesize that due to the long duration of mechanical ventilation in COVID19 patients and the possibility of weaning failure, it may affect the hippocampal function and may lead to cognitive impairment in few years ahead. Further study regarding the effect after the long duration of mechanical ventilation in COVID-19 patients are required to be held, In order to prevent further cognitive deficits by among patients who had experienced mechanical ventilation. Developing an early screening of cognitive functions.

\section{References}

1. Zhou P, Yang XL, Wang XG, Hu B, Zhang L, Zhang W, et al. A pneumonia outbreak associated with a new coronavirus of probable bat origin. Nature. 2020;579(7798):270-3.

PMid:32015507

2. World Health Organization, Coronavirus Disease (COVID-19) Pandemic. Available from: https://www.who.int/emergencies/ diseases/novel-coronavirus-2019. [Last accessed on 2020 Mar 11].

3. Wu Z, McGoogan JM. Characteristics of and important lessons from the coronavirus disease 2019 (COVID-19) outbreak in China: Summary of a report of 72314 cases from the Chinese center for disease control and prevention. JAMA. 2020;323(13):1239-42. https://doi.org/10.1001/jama.2020.2648 PMid:32091533

4. Channappanavar R, Perlman S. Pathogenic human coronavirus infections: Causes and consequences of cytokine storm and immunopathology. Semin Immunopathol. 2017;39(5):529-39. https://doi.org/10.1007/s00281-017-0629-x PMid:28466096

5. Mahdi BM. COVID-19 Type III hypersensitivity reaction. Med Hypotheses 2020;140:109763. https://doi.org/10.1016/j. mehy.2020.109763

PMid:32344307

6. Chen N, Zhou M, Dong X, Qu J, Gong F, Han Y, et al. Epidemiological and clinical characteristics of 99 cases of 2019 novel coronavirus pneumonia in Wuhan, China: A descriptive study. Lancet. 2020;395(10223):507-13. https://doi.org/10.1016/ s0140-6736(20)30211-7

PMid:32007143

7. Huang C, Wang Y, Li X, Ren L, Zhao I, Hu Y, et al. Clinical features of patients infected with 2019 novel coronavirus in Wuhan, China. Lancet. 2020;395(10223):497-506

8. Ko JH, Seok H, Cho SY, Ha YE, Baek JY, Kim SH, et al. Challenges of convalescent plasma infusion therapy in Middle East respiratory coronavirus infection: A single centre experience. Antivir Ther. 2018;23(7):617-22. https://doi. org/10.3851/imp3243

PMid:29923831

9. Hung IF, To KK, Lee CK, Lee KL, Chan K, Yan WW, et al. Convalescent plasma treatment reduced mortality in patients with severe pandemic influenza A (H1N1) 2009 virus infection. Clin Infect Dis. 2011;52(4):447-56.

PMid:21248066

10. Cheng Y, Wong R, Soo YO, Wong WS, Lee CK, Ng MH, et al.
Use of convalescent plasma therapy in SARS patients in Hong Kong. Eur J Clin Microbiol Infect Dis. 2005;24(1):44-6. https:// doi.org/10.1007/s10096-004-1271-9

PMid: 15616839

11. Karthick R, Krishnasamy N, Jayanthi R, Jeyalalitha R, Murugan $\mathrm{N}$, Arunkumar R. Convalescent plasma transfusion for the treatment of COVID-19: Systematic review. J Med Virol. 2020;19. https://doi.org/10.1002/jmv.25961 PMid:32356910

12. Shen $C$, Wang Z, Zhao F, Yang Y, Li J, Yuan J, et al. Treatment of 5 critically ill patients with covid-19 with convalescent plasma. JAMA 2020;323(16):1582-9. https://doi.org/10.1001/ jama.2020.4783

PMid:32219428

13. Zaki $A M$, van Boheemen $S$, Bestebroer $T M$, Osterhaus $A D$, Fouchier RA. Isolation of a novel coronavirus from a man with pneumonia in Saudi Arabia. N Engl J Med. 2012;367(19):181420. https://doi.org/10.1056/nejmoa1211721 PMid:23075143

14. Holshue ML, DeBolt C, Lindquist S, Lofy KH, Wiesman J, Bruce $\mathrm{H}$, et al. First case of 2019 novel coronavirus in the United States. N Engl J Med. 2020;382(10):929-36. https://doi. org/10.1056/NEJMoa2001191

PMid:32004427

15. Chen L, Xiong J, Bao L, Shi Y. Convalescent plasma as a potential therapy for COVID-19. Lancet Infect Dis. 2020;20(4):398-400. https://doi.org/10.1016/s1473-3099(20)30141-9

PMid:32113510

16. Duan K, Liu B, Li C, Zhang H, Yu T, Qu J, et al. Effectiveness of convalescent plasma therapy in severe COVID-19 patients. Proc Natl Acad Sci U S A. 2020;117(17):9490-6. PMid:32253318

17. Shen C, Wang Z, Zhao F, Yang Y, Li J, Yuan J, et al. Treatment of 5 critically ill patients with covid-19 with convalescent plasma. JAMA 2020;323(16):1582-9. https://doi.org/10.1001/ jama.2020.4783 PMid:32219428

18. Carlucci A, Richard JC, Wysocki M, Lepage E, Brochard L. Noninvasive versus conventional mechanical ventilation: An epidemiologicsurvey.AmJRespirCritCareMed.2001;163(4):87480. https://doi.org/10.1164/ajrccm.163.4.2006027 PMid:11282759

19. Demoule A, Girou E, Richard JC, Taille S, Brochard L. Increased use of noninvasive ventilation in French intensive care units. Intensive Care Med. 2006;32(11):1747-55. https://doi. org/10.1007/s00134-006-0229-z

PMid: 16799775

20. Eskandar N, Apostolakos MJ. Weaning from mechanical ventilation. Crit Care Clin. 2007;23(2):263-74. https://doi. org/10.1016/j.ccc.2006.12.002

PMid: 17368170

21. Pustavoitau A, Stevens RD. Mechanisms of neurologic failure in critical illness. Crit Care Clin. 2008;24(1):1-24. https://doi. org/10.1016/j.ccc.2007.11.004

PMid: 18241776

22. Hopkins RO, Jackson JC. Long-term neurocognitive function after critical illness. Chest. 2006;130(3):869-78. https://doi. org/10.1378/chest.130.3.869

PMid: 16963688

23. Pandharipande $P$, Pun BT, Herr DL, Maze M, Girard TD, Miller RR, et al. Effect of sedation with dexmedetomidine vs lorazepam on acute brain dysfunction in mechanically ventilated patients: The MENDS randomized controlled trial. J Am Med Assoc. 2007;298(22):2644-53. https://doi. 
org/10.3410/f.1108479.564543

PMid: 18073360

24. Gonzalvo R, Marti-Sistac O, Blanch L, López-Aguilar J. Benchto-bedside review: Brain-lung interaction in the critically ill-a pending issue revisited. Crit Care. 2007;11(3):216. https://doi. org/10.1186/cc5930

PMid:17581271

25. Stawicki SP. Mechanical ventilation: Weaning and extubation. OPUS 12 Sci. 2007;1(2):13-6.

26. Hopkins SJ. Central nervous system recognition of peripheral inflammation: A neural, hormonal collaboration. Acta Biomed. 2007;78(1):231-47.

PMid: 17465337

27. Capurn L, Miller $\mathrm{AH}$. Immune system to brain signaling: Neuropsychopharmacological implication. Pharmacol Ther. 2011;130(2):226-38.

PMid:21334376

28. Coplin WM, Pierson DJ, Cooley KD, Newell DW, Rubenfeld GD. Implications of extubation delay in brain-injured patients meeting standard weaning criteria. Am J Respir Crit Care Med. 2000;161(5):1530-6.https://doi.org/10.1164/ajrccm.161.5.9905102 PMid: 10806150

29. Stevens RD. The brain-lung axis. Intensive Care Med. 2011;37(7):1054-6.

\section{PMid:21544691}

30. Tracy MF, Chlan L. Nonpharmacological interventions to manage common symptoms in patients receiving mechanical ventilation. Crit Care Nurse. 2011;31(3):19-28. https://doi. org/10.4037/ccn2011653

PMid:21632591

31. Hunter BC, Oliva R, Sahler OJ, Gaisser D, Salipante DM, Arezina $\mathrm{CH}$. Music therapy as an adjunctive treatment in the management of stress for patients being weaned from mechanical ventilation. J Music Ther. 2010;47(3):198-219. https://doi.org/10.1093/jmt/47.3.198

PMid:21275332

32. Lee $\mathrm{CH}$, Chang SH, Wang SM, Lai CH, Lai LM. The effects of a musical intervention on the anxiety level of mechanical ventilation patients: A pilot study. Cheng Ching Med J. 2015;11:31-8.

33. Lee OK, Chung YF, Chan MF, Chan WM. Music and its effect on the physiological responses and anxiety levels of patients receiving mechanical ventilation: A pilot study. J Clin Nurs. 2005;14(5):60920. https://doi.org/10.1111/j.1365-2702.2004.01103.x PMid:15840076

34. Blackwood B. The art and science of predicting patients readiness for weaning from mechanical ventilation. Int $\mathrm{J}$ Nurs Stud. 2000;37(2):145-51.

PMid:10684956 